\title{
The World Hospital Pharmacy Research Consortium-Monitoring Global Practice in Relation to the Basel Statements
}

\author{
Rebekah Moles, Betty Chaar, and Jonathan Penm
}

$\mathrm{H}$ ospital pharmacists have an important and unique role in health care, one that significantly affects patient outcomes. However, the majority of published literature has been based on hospital pharmacy practice models in the developed world.

The Basel Statements were the result of an inaugural global conference held in Basel, Switzerland, in 2008, hosted by the Hospital Pharmacy Section of the International Pharmaceutical Federation. These global consensus statements reflect the profession's preferred vision for hospital pharmacy. ${ }^{1}$ Currently, the 75 statements (covering all areas of the medication-use process in hospitals, including medicine procurement, influences on prescribing medicines, preparation and delivery of medicines, administration of medicines, monitoring of medication practice, and human resources and training) are undergoing minor updating, with revisions to be completed this year, while the general principles of evidence-based practices and medication safety will remain unchanged.

Statements or guidelines, however, are relevant only when they are translated into practice and only when individuals and organizations strive to meet the standards set out in them. In addition, it is known that monitoring practice is an essential part of quality assurance and the only way to tell whether interventions are effective in generating change. For these reasons, the World Hospital Pharmacy Research Consortium (WHoPReC) has been established to monitor global hospital pharmacy practice in relation to the Basel Statements. ${ }^{2}$

This issue of CJHP, like previous issues, has a strong focus on content reflected in the Basel Statements. For example, Mackenzie and others ${ }^{3}$ found that nonstandard enteral dosing of nimodipine for aneurysmal subarachnoid hemorrhage was associated with vasospasm. This research gives pharmacists evidence-based ammunition to educate physicians and other hospital staff about best medication-use practices. As such, it supports Basel Statement 14, which states that "Hospital pharmacists should provide orientation and education to nurses, physicians, and other hospital staff regarding best practices for medicines use."1 Furthermore, Basel Statement 56 ("Hospital pharmacists should ensure the development of quality assurance strategies for medicines administration, including

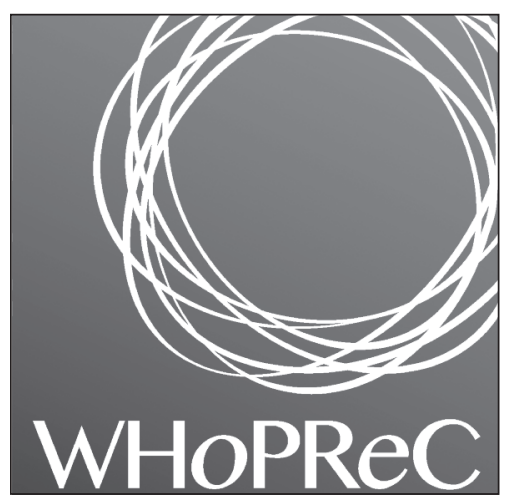
the use of observation methodology to detect errors and identify priorities for improvement"1) was the basis for the process that Mackenzie and others ${ }^{3}$ undertook in their research. Other Basel Statements within the administration theme are currently being explored by WHoPReC members from the Americas, and qualitative interviews with pharmacists in both North and South America are aiming to identify statements that pose difficulties for hospital pharmacists, so that intervention strategies can be trialled in the future.

The topical issue of medication shortages is also covered in the Basel Statements, as shortages affect both developed and developing countries. Basel Statement 25 states that "Each pharmacy should have contingency plans for medicines shortages and purchases in emergencies." In this issue, Barthélémy and others ${ }^{4}$ present a further update on the drug shortage situation in Canada for September 2012 to August 2013, with comparisons to data for 2006-2012. Although they report that fewer drugs were in shortage in 2012-2013, concerns remain about the quality and safety of medications manufactured abroad. Barthélémy and others ${ }^{4}$ recommend that all hospitals keep a safe buffer of 60 days' worth of critical drugs to alleviate the potential effects of drug shortages. Such recommendations ensure that hospital pharmacists meet the standards presented in the Basel 
Statements. Given that medicine shortages are affecting patients globally, the WHoPReC has also initiated research in this area. A Canadian graduate student who is completing a higher research degree at The University of Sydney, in Sydney, Australia, has been focusing on the complexities of the supply chain and exploring the vulnerabilities that exist from the perspective of key opinion leaders. She has been exploring whether the concept of an "essential medicines list", a tool that is extensively used in the developing world, has applicability in developed countries such as Australia and Canada. A student from Nepal, also at The University of Sydney, is looking at the procurement-related Basel Statements, with a particular focus on ethical procurement, which is often an issue in developing nations such as Nepal.

Although hospital pharmacists should maintain their responsibility for procurement of medicines, many have also taken on more clinically focused roles that influence prescribing. Seven statements within the Basel Statements promote hospital pharmacists' influences on prescribing, with statement 32 envisioning that "postgraduate clinical courses should be developed to prepare hospital pharmacists for collaborative prescribing of medicines. ..." However, pharmacists, like their medical counterparts, are at risk of inappropriate prescribing, and this issue's Point Counterpoint debate ${ }^{5,6}$ highlights both the pros and cons of prescribing by hospital pharmacists. Regardless of readers' views on whether pharmacists should prescribe, these health care professionals certainly have an influence on prescribing, and WHoPReC has conducted several studies on this topic in the Western Pacific Region, as numerous countries in Asia are beginning to implement clinical pharmacy services in their hospitals. ${ }^{7}$ Such research has led to the development of validated research instruments to monitor hospital pharmacists' influences on prescribing in 37 countries. ${ }^{7-9}$ This research has further highlighted that, although hospital pharmacists' skills and motivation are required to implement new services, support from hospital administrators, doctors, and patients is also crucial for their success. ${ }^{10,11}$ Therefore research focusing on gaining support for hospital pharmacists to influence prescribing is crucial, from both local and international perspectives.

With WHoPReC aiming to produce high-quality, internationally focused research on hospital pharmacy practices to improve health outcomes, additional research is being conducted. ${ }^{2}$ This research has expanded in scope to focus on additional themes of the Basel Statements in other world regions. For instance, WHoPReC researchers from the African region are focusing on the preparation and distribution of medicines, whereas in the Eastern Mediterranean region, the focus is on human resources and training.

Global research has continued to demonstrate that the Basel Statements are relevant for both developed and developing countries. WHoPReC's work has highlighted areas of hospital pharmacy practice that still need improvement, regardless of a country's development status. We encourage other researchers interested in international hospital pharmacy to contact WHoPReC and participate in this movement. With globalization and increased patient expectations, individual hospital pharmacists must look outside their countries' borders to find innovative ways to practice. We hope that WHoPReC will facilitate international developments in hospital pharmacy practice and deliver improved patient-centred outcomes around the world.

\section{References}

1. The Basel Statements on the future of hospital pharmacy. Am J Health Syst Pharm. 2009;66(5 Suppl 3):S61-6.

2. World Hospital Pharmacy Research Consortium [website]. Sydney (Australia): University of Sydney; 2014 [cited 2014 Aug 13]. Available from: www. whoprec.org

3. MacKenzie M, Gorman SK, Doucette S, Green R. Incidence of and factors associated with manipulation of nimodipine dosage in patients with aneurysmal subarachnoid hemorrhage. Can J Hosp Pharm. 2014;67(5):358-65.

4. Barthélémy I, Lebel D, Bussières JF. Drug shortages in health care institutions: perspectives in early 2014. Can J Hosp Pharm. 2014;67(5):387-9.

5. Mansell H. Should hospital pharmacists prescribe? The "pro" side. Can J Hosp Pharm. 2014;67(5):390-2.

6. Hopf Y. Should hospital pharmacists prescribe? The "con" side. Can J Hosp Pharm. 2014;67(5):392-3.

7. Penm J, Chaar B, Rose G, Moles R. Pharmacists' influences on prescribing: validating a clinical pharmacy services survey in the Western Pacific Region. Res Social Adm Pharm. 2014 Jun 19. doi: 10.1016/j.sapharm.2014.04.001 [Epub ahead of print].

8. Penm J, Chaar B, Moles R. Developing a validated survey to assess the Basel Statements: the Western Pacific Region's response. Int Pharm J. 2010; 26(2):34-8.

9. Penm J, Chaar B, Moles R. Validating a hospital medicines formulary survey in the Western Pacific Region—a global hospital pharmacy initiative based on the Basel Statements. Res Social Adm Pharm. 2012;8(4):298-308.

10. Penm J, Chaar B, Dechun J, Moles R. Formulary systems and pharmacy and therapeutics committees in the Western Pacific Region: exploring two Basel Statements. Am J Health Syst Pharm. 2013;70(11):967-79.

11. Penm J, Moles R, Wang H, Li Y, Chaar B. Factors affecting the implementation of clinical pharmacy services in China. Qual Health Res. 2014;24(3):345-56.

Rebekah J Moles, BPharm, DipHospPharm, PhD, GradCertEdStud (HigherEd), is with the Faculty of Pharmacy, The University of Sydney, Sydney, Australia. She is also an Associate Editor with the CJHP.

Betty Chaar, BPharm, MHL, PhD, is with the Faculty of Pharmacy, The University of Sydney, Sydney, Australia.

Jonathan Penm, BPharm(Hons), is with the Faculty of Pharmacy, The University of Sydney, Sydney, Australia.

Competing interests: All authors are founding members of the World Hospital Pharmacy Research Consortium, an independent global network of researchers that is run on a volunteer basis. No other competing interests declared.

Address correspondence to:

Dr Rebekah J Moles

Faculty of Pharmacy

The University of Sydney

Pharmacy and Bank Building A15

Sydney NSW 2006 Australia

e-mail: rebekah.moles@sydney.edu.au 